\title{
Neonatal Thrombocytopenia
}

National Cancer Institute

\section{Source}

National Cancer Institute. Neonatal Thrombocytopenia. NCI Thesaurus. Code C98995.

A condition characterized by a decrease in the number of platelets in the blood below established reference ranges in a newborn. 